\title{
Outcome of maple syrup urine disease
}

\author{
E R NAUGHTEN, J JENKINS, D E M FRANCIS, AND J V LEONARD \\ Institute of Child Health and The Hospital for Sick Children, London
}

SUMmaRY The outcome of 12 children with classical maple syrup urine disease is reviewed. All patients presented in the neonatal period at ages varying from 5 to 21 (median 8 ) days. The time taken to make the diagnosis ranged from 1 day to longer than 9 months (median 7 days). Each survived his initial illness but 3 died later after apparently mild infections. Three of the 12 patients had a spastic quadriplegia and 6 others abnormal neurological signs without clear cerebral palsy. The single most important factor determining the outcome appears to be the time taken to make the diagnosis after the first symptoms. Two patients were diagnosed within 24 hours of the first symptoms and one is of above average ability. The other is mildly retarded but control of the disease was poor in his first 4 years of life. Outcome is unpredictable if the delay is between 3 and 14 days. Two children are of normal ability but 6 others are retarded. A delay longer than 14 days is invariably associated with mental retardation and cerebral palsy. We conclude that early diagnosis is essential to improve the outcome of this condition.

Maple syrup urine disease (MSUD) is caused by an inborn error of the catabolism of the branched chain amino-acids (BCAA)-leucine, isoleucine, and valine-and commonly presents in the neonatal period with an overwhelming illness. Without treatment most patients with this (classical) form of the disease die and any survivors are mentally retarded and thrive poorly. ${ }^{12}$ Even with treatment the prognosis is uncertain as both retardation and cerebral palsy are common, but some patients do well. We have reviewed the progress of patients with classical MSUD who have attended The Hospital for Sick Children, and have examined some of the factors that may affect the outcome.

\section{Patients and methods}

Fifteen patients with MSUD have attended the hospital but 3 have been excluded from the study. One was diagnosed in 1958 before treatment had been fully established and was reported elsewhere. ${ }^{3}$ The remaining 14 were diagnosed after 1969. Two patients, who presented after age 1 year and who tolerated more than $1.2 \mathrm{~g} / \mathrm{kg}$ protein, had variant forms of MSUD and have also been excluded. ${ }^{45}$ The remaining patients form the subject of this report. The diagnosis of MSUD was initially confirmed by finding a pronounced increase in the plasma BCAA concentrations (leucine $>2000 \mu \mathrm{mol} / 1$
$(26 \mathrm{mg} / 100 \mathrm{ml}))$ and the presence of L-alloisoleucin in the plasma together with BCAA and their kete acids in the urine.

All the patients who were alive were examined by one of us (E R N) except for one (Case 5) who lives abroad, information about whom was obtained from a local paediatrician. Details of the patient's initial illness were obtained retrospectively from the casenotes. Psychometric tests were performed by one observer $(\mathrm{J} J)$ but if the child could not be tested personally reports were obtained from other psychologists. For this reason several tests have been used: Griffiths's (for children aged between 0 and 2 years), Merrill Palmer (between 2 and 5 years), or Stanford Binet (between 2 and 7 years), and the Wechsler intelligence scale, revised (WISC-R) (over 7 years). As several tests were used and it is difficult to compare the results we were forced to use a method of comparison which is now regarded as statistically questionable. We have calculated scores on the basis of mental age/chronological age $\times 100$. These scores have then been grouped into broad categories as follows: group $1=>90$; group $2=$ $70-90$; group $3=50-70$; group $4=30-50$; group $5=$ below 30 .

All patients were treated with a diet that contained controlled quantities of BCAA. This is monitored by measuring the BCAA concentrations, initially at weekly intervals but as the children grew this was 
done monthly. Until 1975, the amino-acid concentrations were measured by a semiquantitative method but since 1975 the estimations have been performed on an amino-acid analyser (Rank Hilger Chromospek). We aim to maintain the plasma leucine at between 100 and $700 \mu \mathrm{mol} / 1 \dagger$ and the isoleucine and valine at between 50 and $400 \mu \mathrm{mol} / 1 . \dagger$

The mean leucine intake for each patient has been calculated during a 3-month period around birthdays using the dietetic records. Complete dietary information was available during any hospital admission and for the periods at home the intake was calculated from the quantity of cows' milk and the number of exchanges of natural protein that the child was receiving (1 exchange is about equal to

†Normal plasma concentrations of the branched chain aminoacids depend on several factors including protein intake. ${ }^{13}$ Mean (SD) non-fasting leucine 141 (41) $\mu \mathrm{mol} / \mathrm{l}$, isoleucine 59 (18), valine 213 (57).
$300 \mu \mathrm{mol}(40 \mathrm{mg})$ leucine) ${ }^{6}{ }^{7}$ Periods of minor illness were included, but any illness that required intravenous therapy or the use of the emergency regimen for longer than 5 days was omitted.

\section{Results}

Presentation and diagnosis. All 12 patients developed symptoms in the neonatal period. The age at which these children presented varied between 5 and 21 (median 8) days, but the time taken to make the diagnosis ranged from 1 day to $>9$ months (median 7 days) (Table 1). The 2 children with the longest delay both came from overseas (Cases 6 and 11). All the patients had some neurological signs that ranged from marked hypotonia to hypertonia with 'fisting' and twitching. However, signs varied considerably even in the same baby. Only 2 patients (Cases 5 and 7) were observed to have fits. Eight of the patients required assisted ventilation (Table 1). Poor feeding

Table 1 Details of the initial illness of the patients with maple syrup urine disease

\begin{tabular}{|c|c|c|c|c|c|c|}
\hline Case & $\begin{array}{l}\text { Age at first } \\
\text { symptoms (days) }\end{array}$ & $\begin{array}{l}\text { Delay in } \\
\text { diagnosis } \\
\text { (days) }\end{array}$ & $\begin{array}{l}\text { Initial plasma leucine } † \\
(\mu \mathrm{mol} / \mathrm{l})\end{array}$ & $\begin{array}{l}\text { Days for } \\
\text { leucine to fall } \\
\text { below } 1000 \mu \mathrm{mol} / \mathrm{l}\end{array}$ & $\begin{array}{l}\text { Neurological } \\
\text { signs }\end{array}$ & $\begin{array}{l}\text { Assisted } \\
\text { ventilation }\end{array}$ \\
\hline $\begin{array}{r}1 \\
2 \\
3 \\
4 \\
5 \\
6 \\
7 \\
8 \\
9 \\
10 \\
11 \\
12\end{array}$ & $\begin{array}{r}6 \\
7 \\
7 \\
14 \\
7 \\
14 \\
9 \\
5 \\
9 \\
8 \\
21^{*} \\
14\end{array}$ & $\begin{array}{l}5 \\
1 \\
9 \\
\text { Not known } \\
5 \\
285 \\
1 \\
10 \\
7 \\
3 \\
30 \\
14\end{array}$ & $\begin{array}{l}2420 \\
3800 \\
3550 \\
\text { Not known } \\
5300 \\
5000 \\
4000 \\
4000 \\
6450 \\
4000 \\
3000 \\
3350\end{array}$ & $\begin{array}{l}10 \\
2 \\
16 \\
\text { Not known } \\
4 \\
2 \\
4 \\
6 \\
15 \\
10 \\
5 \\
12\end{array}$ & $\begin{array}{l}\text { Areflexia } \\
\text { Areflexia, hypotonia } \\
\text { Hypertonia, irritability } \\
\text { Hypertonia, irritability } \\
\text { Hypotonia, irritability } \\
\text { Irritability } \\
\text { Hypertonia, fisting } \\
\text { Hypotonia, hypertonia, areflexia } \\
\text { Hypertonia, fisting } \\
\text { Hypotonia } \\
\text { Hypotonia } \\
\text { Hypertonia, irritability, areflexia }\end{array}$ & $\begin{array}{l}\text { Yes } \\
\text { Yes } \\
\text { Yes } \\
\text { No } \\
\text { No } \\
\text { No } \\
\text { Yes } \\
\text { Yes } \\
\text { Yes } \\
\text { Yes } \\
\text { No } \\
\text { Yes }\end{array}$ \\
\hline
\end{tabular}

*Approximate, tmedian plasma leucine concentrations in healthy breast-fed newborn ${ }^{12}=103$ (range $61-183$ ) $\mu$ mol/1.

Conversion: SI to traditional units-leucine $1 \mu \mathrm{mol} / 1 \approx 0.013 \mathrm{mg} / 100 \mathrm{ml}$.

Table 2 Mean leucine intake at 2 years, outcome, neurological status, and intellectual performance of patients with maple syrup urine disease

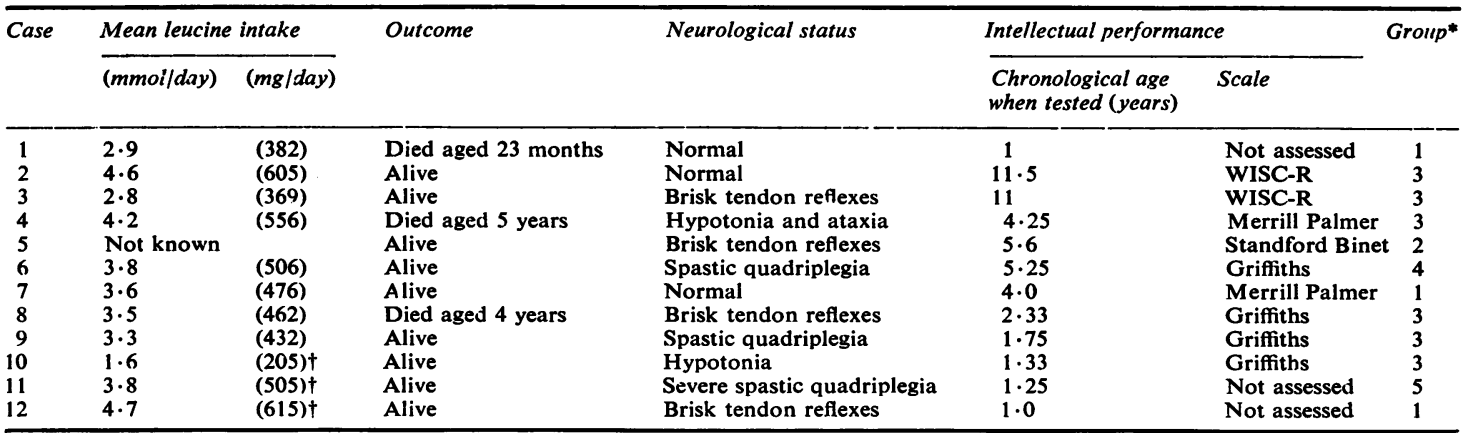

*For explanation see text; +Cases 10,11 , and 12 -assessment of leucine intake at 18, 15, and 11 months respectively;

W ISC-R-Wechsler intelligence scale (revised) for children. 
and a weak suck was present in all patients but in none was vomiting noted.

The leucine concentrations at the time of diagnosis exceeded $2400 \mu \mathrm{mol} / 1$ in all cases (Table 1). The treatment that was used to control the accumulation of BCAA was not standardised and included both exchange transfusions and peritoneal dialysis. The efficiency of the treatment has been measured by the time taken for the leucine level to fall below 1000 $\mu \mathrm{mol} / 1$ and was between 2 and 16 (median 6 ) days (Table 1). The patients were then established on the diet and the leucine intake adjusted according to the plasma BCAA levels. At age 2 years the mean leucine intake was $3.5 \mathrm{mmol} / 24 \mathrm{~h}(461 \mathrm{mg} / 24 \mathrm{~h})$ (Table 1$)$.

All children have had further admissions to hospital during periods of intercurrent infection or to help with feeding difficulties but, except for those who died, none of the children with the classical form has been comatose, although ataxia, slurring of speech, and drowsiness were common.

Outcome. All patients survived the initial illness but 3 patients died later. The condition of one child (Case 1) deteriorated rapidly after a short bout of diarrhoea and vomiting and she died aged 23 months despite intensive treatment including peritoneal dialysis. The second child (Case 4) died aged $5 \frac{3}{4}$ years after an influenzal illness with vomiting from which he appeared to be recovering but his condition deteriorated suddenly and he failed to respond to intensive treatment. The third child (Case 8) died recently aged $4 \frac{3}{4}$ years after mild gastroenteritis for 24 hours. All three children had been well controlled until their final illness. In two patients (Cases 1 and 4) plasma leucine levels rose rapidly in $24-48$ hours to more than $2500 \mu \mathrm{mol} / 1(>33 \mathrm{mg} / 100 \mathrm{ml})$ and although these were reduced by treatment the patients died.

Three of the 9 survivors have cerebral palsy all having spastic quadriplegia and 4 other children have abnormal neurological signs without clear evidence of cerebral palsy. Three have brisk tendon reflexes and one is hypotonic. Although the other 2 have no abnormal neurological signs, one is clumsy. Of the 3 patients who have died, one was hypotonic and mildly ataxic, one had brisk reflexes, and the third was described in the case-notes as normal.

Intellectual performance. Four patients could not be assessed by us; three (Cases 1, 4, and 8 ) had died, and one (Case 5) lives abroad, and for these patients we had to rely on the reports from other psychologists and paediatricians. Cases 11 and 12 were examined by a paediatrician (E R N) only, but the rest were formally assessed.

Only one child (Case 7) who is still alive is unequivocally normal. Another child (Case 12) is $\bigcirc$ within normal limits at present but there remains some uncertainty as she is only 1-year old. The majority of children are mildly or moderately $\overrightarrow{\vec{\rho}}$ retarded (groups 3 and 4).

\section{Discussion}

All the patients survived the initial illness but this may represent a selected population since other $\Omega$ patients may have died before they could be referred. $\infty$ Three children died later as a result of intercurrent $\overrightarrow{0}$ infections and in two the final illness was complicated $\vec{\overrightarrow{ }}$ by marked and persistent hypokalaemia (plasma $\vec{\sigma}$ potassium $<1.5 \mathrm{mmol} / \mathrm{l})$, the cause of which is unknown.

The outcome of patients with MSUD has of improved since the early reports. In the Canadian $\vec{\sim}$ multicentre survey 6 of the 9 patients with classical $\underset{0}{N}$ MSUD had IQ (or DQ) scores of over $70,{ }^{8}$ and in a $\underset{\infty}{\overrightarrow{0}}$ recent study from Quebec all 4 children were $\circ$ developmentally normal. ${ }^{9}$ In another collaborative study 3 of 6 survivors who were started on diet when $\vec{\nabla}$ aged less than 2 weeks were described as normal. ${ }^{10} \Phi$ In our study however, the patients have not done so $\frac{\Phi}{3}$ well. Of the survivors only one is unequivocally normal and 2 others were probably normal but one died and the other was not formally assessed. All th\& $\vec{\oplus}$ remaining patients are retarded, ranging from milde to severely so.

It is probable that there are many different factor that influence the outcome and it is not easy to determine which of these are important. However, a prolonged delay in making the diagnosis of the $\frac{\circ}{\mathbb{Q}}$ classical form of MSUD is invariably associated $\stackrel{\varrho}{\rightarrow}$ with mental retardation and cerebral palsy, and the $\overrightarrow{\overrightarrow{0}}$ 2 patients in whom the diagnosis was delayed longer 3 than 30 days were both severely handicapped. In the Quebec study ${ }^{8}$ intensive treatment was started in all the patients within 24 hours of the onset of symptoms. Two (Cases 2 and 7) of our patients had similarly rapid diagnosis and treatment. One whose $\frac{5}{3}$ subsequent control has been good is of above average ability and is neurologically normal. The second had $\frac{0}{3}$ erratic control for the first 4 years of life and now

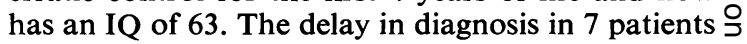
was between 3 and 14 days and the outcome was $D$ unpredictable, 2 of the children were probably normal, the others were borderline or retarded. Two No children developed normally despite severe encephalopathy that required assisted ventilation in 0 the neonatal period.

The plasma leucine concentrations on admission reflect the dietary protein intake and any initialo

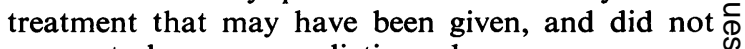
appear to have any predictive value.

The time taken for leucine to fall below 1000 T 
$\mu \mathrm{mol} / \mathrm{l}$ varied from 2 to 16 days but this did not appear to influence the outcome. In 5 patients this interval was at least 10 days and 2 of these (Cases 1 and 12) have done well but the other 3 (Cases 3, 9, and 10) are retarded, two of them severely so.

After the neonatal period the full extent of the neurological abnormalities gradually became apparent in a manner typical of cerebral palsy but in no child has there been evidence of further progression. Rather, there has been improvement in the child (Case 6) whose treatment started very late.

The quality of the dietary control after the neonatal period is difficult to assess. Plasma BCAA concentrations have not been measured regularly during periods of intercurrent infection and isolated values may give a false impression of the quality of control since levels fluctuate widely even if the child is well. We have noted levels greater than 1000 $\mu \mathrm{mol} / \mathrm{l}$ of leucine in seemingly healthy children.

After the initial illness all patients were readmitted during minor illnesses but the number of admissions to hospital is not a good index of control because the admissions are often a reflection of the ability of the family to cope under stress as much as of the child's condition. Nevertheless the control of Case 11 who lives abroad is known to be particularly poor, and this child has made little developmental progress. The quality of dietary control of the 2 oldest patients (Cases 2 and 3 ) was not good during the early years but since then the quality of control has improved and has been generally similar in all patients. The IQ of the older patients has been tested regularly and has remained stable over several years.

As the Quebec group has shown, ${ }^{8}$ it is possible to achieve good results with the treatment of MSUD and we would tentatively suggest that the single most important factor is early diagnosis. When a term neonate becomes ill the possibility of a metabolic disorder needs to be considered early and even the history may provide clues. In our patients, there were no fewer than 10 children who had died in the neonatal period in 6 of the 10 families. In only one of these children had the diagnosis of MSUD been made. The early signs of illness in the neonatal period are not specific and many of the patients were thought initially to have had septicaemia. Not all patients have had pronounced metabolic acidosis. At the time of admission, 5 patients (Cases 1, 7, 8, 9, and 10) were acidotic (pH $<7.25$ and plasma bicarbonate $<10 \mathrm{mmol} / 1$ or base deficit $>9 \mathrm{mmol} / \mathrm{l}$ ), but many of the patients had already received some treatment including unspecified quantities of sodium bicarbonate.

If the diagnosis is to be made earlier, tests for metabolic disease will need to be done at the same time as the screen for infection. The results of urine screening tests on admission were recorded in 7 of the 12 patients. Ketonuria was present in only 4 patients with an equivocal result in one other patient, but there was a precipitate with 2,4-dinitrophenylhydrazine which detects $\alpha$-keto-acids ${ }^{11}$ in all 7 patients. This finding would indicate the need for urgent investigation that would include determination of the plasma and urinary amino-acids and urinary organic acids. Once a metabolic disorder is suspected intensive treatment is indicated to control the metabolic derangement, even before the precise diagnosis is known.

We thank Dr D M Johnston, Dr G Rajan, Dr $\mathrm{S}$ Tsagaraki, and Professor $\mathrm{O} \mathbf{H}$ Wolff for their co-operation and for allowing us to include the patients under their care; Dr J W T Seakins and Mr R S Ersser for their excellent laboratory service.

\section{References}

1 Menkes J H, Hurst P L, Craig J M. A new syndrome: progressive familial infantile cerebral dysfunction associated with an unusual urinary substance. Pediatrics 1954; 14: 462-6.

2 Dickinson J P, Holton J B, Lewis G M, Littlewood J M, Steel A E. Maple syrup urine disease. Acta Paediatr Scand 1969; 58: 341-51.

3 Mackenzie D Y, Woolf L I. 'Maple syrup urine disease': an inborn error of the metabolism of valine, leucine, and isoleucine associated with gross mental deficiency. Br MedJ 1959; i: $90-1$.

4 Dancis J, Hutzler J, Rokkones T. Intermittent branchedchain ketonuria. $N$ Engl J Med 1967; 276: 84-9.

5 Kiil R, Rokkones T. Late manifesting variant of branchedchain ketoaciduria (maple syrup urine disease). Acta Paediatr Scand 1964; 53: 356-64.

6 Francis D E M. Diets for sick children, third edition. Oxford: Blackwell, 1974.

7 Paul A A, Southgate D A T, Russell J. McCance and Widdowson's the composition of foods. supplement 1 . London: HMSO, 1980.

8 Committee for Improvement of Hereditary Disease Management. Management of maple syrup disease in Canada. Can Med Assoc J 1976; 115: 1005-13.

- Clow C L, Reade T M, Scriver C R. Outcome of early and long-term management of classical maple syrup urine disease. Pediatrics 1981; 68: 856-62.

10 Naylor E W, Guthrie R. Newborn screening for maple syrup urine disease (branched-chain ketoaciduria). Pediatrics 1978; 61: 262-6.

11 Buist N R M, Kennaway N G. Metabolic disorders. In: Forfar J O, Arneil G C, eds. Textbook of paediatrics, second edition. Edinburgh: Churchill Livingstone, 1978: 1038.

12 Pohlandt F. Plasma amino acids of newborn infants breast-fed ai libitum. J Pediatr 1978; 92: 614-6.

13 Clayton B E, Jenkins P, Round J M, Paediatric chemical pathology: clinical tests and reference ranges. Oxford: Blackwell, 1980.

Correspondence to Dr J V Leonard, Department of Child Health, Institute of Child Health, 30 Guilford Street, London WC1N 1EH.

Received 15 September 1982 